\title{
Clinical and cardiac magnetic resonance findings in post-COVID patients referred for suspected myocarditis
}

\author{
Philipp Breitbart ${ }^{1,2,3}$ - Alexander Koch ${ }^{1,3} \cdot$ Marco Schmidt $^{1,3} \cdot$ Annett Magedanz ${ }^{1,3}$. Edelgard Lindhoff-Last ${ }^{1,3}$. \\ Thomas Voigtländer ${ }^{1,3} \cdot$ Axel Schmermund $^{1,3} \cdot$ Rajendra H. Mehta ${ }^{4} \cdot$ Holger Eggebrecht $^{1,3}$
}

Received: 8 June 2021 / Accepted: 16 August 2021 / Published online: 26 August 2021

(C) The Author(s) 2021

\begin{abstract}
Objectives We assessed possible myocardial involvement in previously cardiac healthy post-COVID patients referred for persisting symptoms with suspected myocarditis.

Background Prior studies suggested myocardial inflammation in patients with coronavirus-induced disease 2019 (COVID19). However, the prevalence of cardiac involvement among COVID patients varied between 1.4 and $78 \%$.

Methods A total of 56 post-COVID patients without previous heart diseases were included consecutively into this study. All patients had positive antibody titers against SARS-CoV-2. Patients were referred for persistent symptoms such as chest pain/ discomfort, shortness of breath, or intolerance to activity. All patients underwent standardized cardiac assessment including electrocardiogram (ECG), cardiac biomarkers, echocardiography, and cardiac magnetic resonance (CMR).

Results 56 Patients ( $46 \pm 12$ years, $54 \%$ females) presented $71 \pm 66$ days after their COVID-19 disease. In most patients, the course of COVID-19 was mild, with hospital treatment being necessary in five (9\%). At presentation, patients most often reported persistent fatigue (75\%), chest pain (71\%), and shortness of breath (66\%). Acute myocarditis was confirmed by T1/ T2-weighed CMR and elevated NTpro-BNP levels in a single patient (2\%). Left ventricular ejection fraction was $56 \%$ in this patient. Additional eight patients (14\%) showed suspicious CMR findings, including myocardial edema without fibrosis $(n=3)$, or non-ischemic myocardial injury suggesting previous inflammation $(n=5)$. However, myocarditis could ultimately not be confirmed according to 2018 Lake Louise criteria; ECG, echo and lab findings were inconspicuous in all eight patients. Conclusions Among 56 post-COVID patients with persistent thoracic complaints final diagnosis of myocarditis could be confirmed in a single patient using CMR.
\end{abstract}

Philipp Breitbart

p.breitbart@ccb.de

1 Cardioangiological Center Bethanien (CCB), Im Prüfling 23, 60389 Frankfurt, Germany

2 Division of Cardiology and Angiology II, University Heart Center Freiburg-Bad Krozingen, University Hospital Freiburg, Bad Krozingen, Germany

3 AGAPLESION Bethanien Hospital, Frankfurt, Germany

4 Duke Clinical Research Institute (DCRI), Durham, NC, USA 


\section{Graphic abstract}

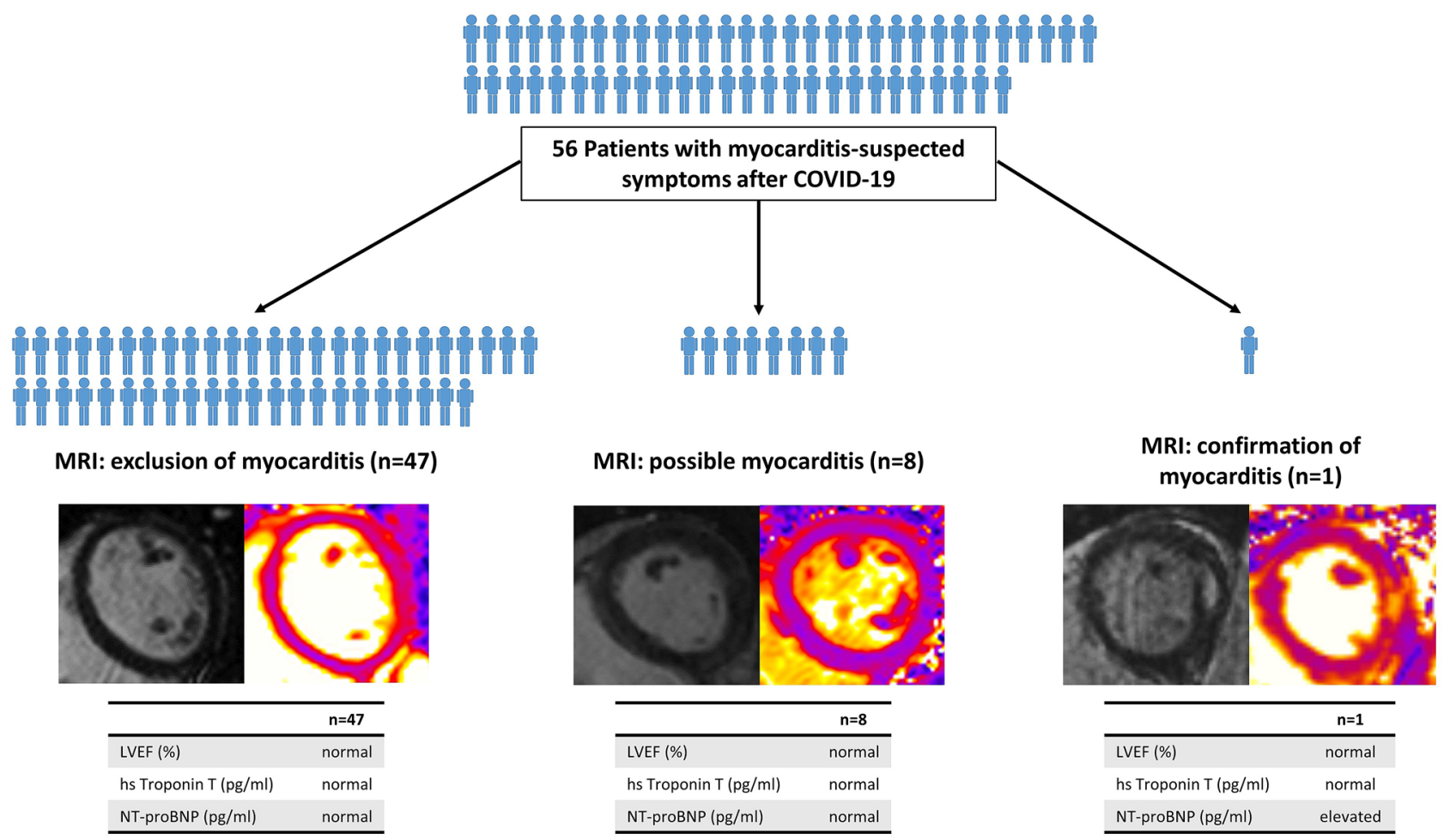

Keywords COVID-19 $\cdot$ Myocarditis $\cdot$ Myocardial inflammation $\cdot$ Cardiac imaging $\cdot$ MR-tomography

$\begin{array}{ll}\text { Abbreviations } & \\ \text { CK } & \text { Creatine kinase } \\ \text { CMR } & \text { Cardiovascular magnetic resonance } \\ \text { COI } & \text { Cut-off index (COI) } \\ \text { COVID-19 } & \text { Coronavirus-induced disease 2019 } \\ \text { ECG } & \text { Electrocardiogram } \\ \text { ECV } & \text { Extracellular volume } \\ \text { hsTnT } & \text { High-sensitivity troponin T } \\ \text { LGE } & \text { Late gadolinium enhancement } \\ \text { NT-proBNP } & \text { N-terminal pro-b-type natriuretic peptide } \\ \text { PCR } & \text { Polymerase chain reaction } \\ \text { SARS-CoV-2 } & \text { Severe acute respiratory syndrome } \\ & \text { coronavirus-2 }\end{array}$

\section{Introduction}

Early in the severe acute respiratory syndrome coronavirus-2 (SARS-CoV-2) pandemic, individual case reports and smaller case series suggested that coronavirus-induced disease 2019 (COVID-19) can lead to deterioration of cardiac function in patients with previous cardiovascular diseases [1-3].
Previous studies using cardiovascular magnetic resonance (CMR) imaging which is considered the gold standard for non-invasive myocarditis diagnosis [4], provided conflicting results on the prevalence of COVID-19 associated myocarditis ranging between $1.4 \%$ [5] and as high as $58-78 \%$ of patients [6, 7].

In clinical practice we are often confronted with postCOVID patients without previous cardiac diseases who suffer from persistent thoracic complaints, exertional dyspnea and/or exercise intolerance, even months after their SARSCoV-2 infection. Data specifically for this increasing group of patients are scarce. Therefore, we aimed to investigate the prevalence of myocardial inflammation in post-COVID patients without previous cardiac diseases, referred for suspicion of myocarditis.

\section{Methods}

\section{Study population}

Consecutive patients with no history of previous cardiac disease who were referred with persistent symptoms suspicious of myocarditis such as chest pain/discomfort, shortness 
of breath, intolerance to activity, dizziness and/or palpitations since their COVID-19 disease were included into the study. Diagnosis of COVID-19 was based on a previous positive polymerase chain reaction (PCR) test and positive SARS-CoV-2 IgM/IgG antibodies directed against the viral nucleocapsid antigen (Elecsys ${ }^{\circledR}$ Anti-SARS-CoV-2, Roche; negative $=$ cut-off index $(\mathrm{COI})<1)$. Exclusion criteria were (1) known or newly diagnosed non-inflammatory heart disease, (2) contraindications for performing CMR with contrast media (e.g., claustrophobia, contrast medium allergy, glomerular filtration rate $\leq 30 \mathrm{ml} / \mathrm{min} / 1.73 \mathrm{~m}^{2}$, implants or devices without admission for CMR) or insufficient image quality, (3) hemodynamic instability or (4) pregnancy/ lactation.

All patients gave their written informed consent for the anonymized use of clinical, procedural, and follow-up data. The study was approved by the local institutional review board (ethics committee of the Landesärztekammer Hessen) and complies with the Declaration of Helsinki. The study was sponsored by the Foundation of the Working Group of Leading Cardiological Hospital Doctors e.V. (ALKK).

\section{Diagnostic procedures}

All patients completed a dedicated questionnaire to assess their current complaints as well as the symptoms during the acute COVID-19 disease, including a 10-point visual analog scale for individual quantification of COVID-19 severity from "0" (no symptoms) to "10" (most severe course). Patients underwent a standardized cardiologic assessment including 12-lead electrocardiogram (ECG), echocardiographic evaluation of systolic and diastolic left ventricular as well as valvular function, and assessment of laboratory cardiac markers including high-sensitivity troponin T (hsTnT), creatine kinase $(\mathrm{CK})$, and $\mathrm{N}$-terminal pro-b-type natriuretic peptide (NT-proBNP).

\section{Cardiac magnetic resonance imaging}

All patients underwent the CMR examination on a 1,5 Tesla scanner (Magnetom Aera@, Siemens Healthcare $\mathrm{GmbH}$, Erlangen, Germany). Every scan was performed and evaluated jointly by a cardiologist and a radiologist, each certified as having the maximum level of qualification in cardiac MRI from their societies (German Cardiac Society, German Radiological Society). In a standardized protocol, the localizers were followed by evaluation of left ventricular function parameters using a semi-automatic approach (syngo.via (), Siemens Healthcare GmbH, Erlangen, Germany). Using cine images in short-axis (SAX) stack, 2-/3- and 4-chamberview, we evaluated the left ventricular ejection fraction (LVEF) as well as left ventricular end-diastolic volume index (LVEDVI), left ventricular end systolic volume index (LVESVI), left ventricular stroke volume index (LVSVI) and myocardial mass (MM). In addition, T2 darkblood TIRM-Sequences were performed in three views (axial from base to apex, 4- and 2-chamber-view).

T1 mapping was performed using electrocardiographically triggered modified look-locker inversion-recovery (MOLLI) sequence with a 5(3)3 acquisition (five heartbeats of acquisition are followed by three recovery heartbeats which are followed by another three acquisition heartbeats) on three short-axis (basal, midventricular, apical). T2 maps were acquired in the same planes as the T1 maps using the SIEMENS MyoMaps product sequence (Siemens Healthcare GmbH, Erlangen, Germany), which is T2-prepared. T2 map is calculated from three singleshot acquisitions at different times of $\mathrm{T} 2$ preparation $(0 \mathrm{~ms}$, $25 \mathrm{~ms}, 55 \mathrm{~ms})$. Furthermore, T1 maps were created with a 4(1)3(1)2 acquisition on three short-axis (basal, midventricular, apical) approximately $15 \mathrm{~min}$ after contrast agent application to create extracellular volume (ECV) map and T1 error map. Generally, we performed a semi-automatic quantification (cvi42@, Circle Cardiovascular Imaging Inc., Calgary, Canada) of T1, T2 and ECV maps for every of the 16 myocardial segments.

Late gadolinium enhancement (LGE) $(0.2 \mathrm{mmol} /$ $\mathrm{kg}$ Gadolinium [Dotarem $\odot$, Guerbet $\mathrm{GmbH}$, Sulzbach, Germany]) imaging was acquired in the same planes as cine imaging with a phase-sensitive inversion-recovery sequence.

\section{CMR imaging analysis}

Increased $\mathrm{T} 1$ values were defined according to internal reference values as greater than $1077 \mathrm{~ms}$ (basal), $1083 \mathrm{~ms}$ (midventricular) or $1081 \mathrm{~ms}$ (apical) and T2 mapping values greater than $50 \mathrm{~ms}$ (basal), $51 \mathrm{~ms}$ (midventricular) or $53 \mathrm{~ms}$ (apical), respectively. These sequence-specific cutoffs have previously been defined as laying 2 SDs above the respective means in a healthy population. Significant abnormalities were defined as greater than $1145 \mathrm{~ms}$ (basal), $1153 \mathrm{~ms}$ (midventricular) or $1146 \mathrm{~ms}$ (apical) for T1 and greater than $54 \mathrm{~ms}$ (basal), $56 \mathrm{~ms}$ (midventricular) or $59 \mathrm{~ms}$ (apical) for $\mathrm{T} 2$, using 4 SDs (based on earlier international publications (7)) above those means.

According to the 2018 Lake Louis criteria, myocarditis is diagnosed if both of the main criteria are positive: proof of (1) myocardial edema (T2 mapping or T2 darkblood TIRM-Sequences) and (2) non-ischemic myocardial injury (abnormal T1, ECV or LGE). Only one fulfilled criterion still supports the diagnosis of acute myocardial inflammation in an appropriate clinical scenario. These patients are classified as "MRI possible myocarditis". 


\section{Statistical analysis}

We performed all statistical analyses with SPSS software, Version 25.0 (IBM Corp., Armonk, NY, USA). Categorical data are described as frequencies or percentages and continuous variables as mean with standard deviation or median with interquartile range. We defined a $P$ value $<0.05$ as statistically significant in all tests.

\section{Results}

Between November 2020 and March 2021, 62 post-COVID patients with no history of previously heart disease were referred for evaluation of persistens symptoms suspicious of myocarditis. In five of them we had to interrupt the CMRscan due to progressive claustrophobia symptoms and the image quality was poor in 1.56 patients were included (mean age $46 \pm 12$ years, $54 \%$ female) for final analysis. Baseline characteristics are presented in Table 1.

The most common acute COVID-19 symptoms were headache (79\%), shortness of breath (77\%), and loss of smell or taste (73\%). A hospital treatment due to COVID-19 was necessary in five patients (9\%), but no patient received mechanical ventilation.

Patients presented $71 \pm 66$ days after their COVID-19 disease. All patients had positive SARS-CoV2-antibody $(61.6 \pm 56.7 \mathrm{COI})$. Most often reported complaints included persisting fatigue (75\%), chest pain (71\%), and shortness of breath $(66 \%)$.

Electrocardiogram, echocardiographic, and laboratory chemistry findings are summarized in Table 2. Three patients (5\%) showed ST-changes suspicious of myocarditis. On echocardiography, all patients had a normal ejection fraction (mean $67 \pm 7 \%$ ) without evidence of relevant diastolic dysfunction. In a single patient, mild pericardial effusion was noted. The mean cardiac blood values were $4.3 \pm 1.9 \mathrm{pg} / \mathrm{ml}$ for hsTnT, $94.9 \pm 53.3 \mathrm{U} / \mathrm{l}$ for CK, and 34.5 [23.0;68.5] pg/ml for NT-proBNP.

\section{CMR findings}

CMR results are presented in Table 3 . Using the 16 myocardial segment model, 13 of all 928 segments (1\%) could not be evaluated in T1 maps due to artifacts or thin myocardium, 44 of 928 segments (5\%) in T2 maps. Mean T1 value was $1016.0 \pm 28.2 \mathrm{~ms}$, mean T2 value $46.9 \pm 3.8 \mathrm{~ms}$. Overall, a pathological T1 relaxation time was found in four of the evaluable segments $(0.4 \%)$ and a pathological $\mathrm{T} 2$ relaxation time in 16 segments (2\%). Late gadolinium enhancement was detectable in seven patients (12\%) with subepicardial (five patients), subendocardial (one patient), and intramyocardial (one patient) localisation.
Table 1 Baseline characteristics of the entire study population

\begin{tabular}{|c|c|c|}
\hline & & $\begin{array}{l}\text { All } \\
\text { patients } \\
(n=56)\end{array}$ \\
\hline Age & (years) & $45.7 \pm 12.2$ \\
\hline Female & $n$ & $30(53.6)$ \\
\hline Any previous medication & $n$ & $24(42.9)$ \\
\hline Beta blocker & $n$ & $4(7.1)$ \\
\hline AT1RB & $n$ & $4(7.1)$ \\
\hline ACEI & $n$ & $5(8.9)$ \\
\hline Statin & $n$ & $4(7.1)$ \\
\hline \multicolumn{3}{|l|}{ Acute COVID-19 symptoms } \\
\hline Fever & $n$ & $34(60.7)$ \\
\hline Cough & $n$ & $33(58.9)$ \\
\hline Limb pain & $n$ & $38(67.9)$ \\
\hline Sore throat & $n$ & $20(35.7)$ \\
\hline Cold & $n$ & $20(35.7)$ \\
\hline Headache & $n$ & $44(78.6)$ \\
\hline Shortness of breath & $n$ & $43(76.8)$ \\
\hline Loss of smell of taste & $n$ & $41(73.2)$ \\
\hline Pneumonia & $n$ & $4(7.1)$ \\
\hline Pulmonary artery embolism & $n$ & $1(1.8)$ \\
\hline $\begin{array}{l}\text { Hospital treatment due to COVID- } \\
19\end{array}$ & $n$ & $5(8.9)$ \\
\hline Acute COVID-19 severity score & $(0-10)^{*}$ & $4.7 \pm 2.2$ \\
\hline $\begin{array}{l}\text { Time between positive swab and } \\
\text { MRI }\end{array}$ & (days) & $70.7 \pm 65.9$ \\
\hline \multicolumn{3}{|l|}{ Current symptoms } \\
\hline Fatigue & $n$ & $42(75.0)$ \\
\hline Shortness of breath & $n$ & $37(66.1)$ \\
\hline Chest pain & $n$ & $40(71.4)$ \\
\hline Palpitations & $n$ & $4(7.1)$ \\
\hline Headache & $n$ & $3(5.4)$ \\
\hline Insomnia & $n$ & $3(5.4)$ \\
\hline Cough & $n$ & $3(5.4)$ \\
\hline SARS-CoV2-antibody level & $\mathrm{COI}$ & $61.6 \pm 56.7$ \\
\hline
\end{tabular}

Values are mean \pm standard deviation or $n(\%)$

$A T 1 R B$ Angiotensin-II subtype I receptor blocker, ACEI angiotensin converting enzyme inhibitor, COI cut-off index, COVID-19 coronavirus-induced disease 2019, SARS-CoV-2 severe acute respiratory syndrome coronavirus- 2

*Severity level 0 means no symptoms, level 10 means maximum symptoms

The results of the various cardiac examinations of all patients with abnormal MRI-findings are summarized in Table 4. One patient (2\%) fulfilled both Lake Louise criteria with intramyocardial LGE as well as increased T1 and T2 times (Fig. 1). In this patient, NT-proBNP was increased to $967 \mathrm{pg} / \mathrm{ml}$, but ejection fraction was within the normal range (56\%). 
Table 2 Electrocardiogram, echocardiography, and cardiac markers of the entire study population

All patients $(n=56)$

\begin{tabular}{lll}
\hline ECG findings & & \\
Heart rate & Beats / min & $69.1 \pm 11.8$ \\
QRS time & $\mathrm{Ms}$ & $92.6 \pm 8.6$ \\
$\begin{array}{l}\text { Myocarditis suspicious ST- } \\
\text { changes }\end{array}$ & $N$ & $3(5.4)$ \\
$\begin{array}{l}\text { Bradycardia } \\
\text { Tachycardia }\end{array}$ & $N$ & $4(7.1)$ \\
$\begin{array}{l}\text { Echocardiographic findings } \\
\text { Ejection fraction }\end{array}$ & $N$ & $1(1.8)$ \\
$\begin{array}{l}\text { Left ventricular end-diastolic } \\
\text { diameter }\end{array}$ & $(\%)$ & $67.2 \pm 6.5$ \\
E/E' & $\mathrm{Mm}$ & $46.8 \pm 4.6$ \\
Wall movement disorders & $n$ & $5.6 \pm 1.5$ \\
Pericardial effusion & $n$ & $2(3.6)$ \\
High-sensitivity troponin T & $\mathrm{pg} / \mathrm{ml}$ & $1(1.8)$ \\
Creatine kinase & $\mathrm{U} / 1$ & $94.3 \pm 1.9$ \\
NT-ProBNP & $\mathrm{pg} / \mathrm{ml}$ & $34.5[23.0 ; 68.5]$ \\
\hline
\end{tabular}

Values are mean \pm standard deviation, median [interquartile range] or $n(\%)$

ECG electrocardiogram, NT-proBNP N-terminal pro-b-type natriuretic peptide

*Severity level 0 means no symptoms, level 10 means maximum symptoms
In eight (14\%) patients, only one of both criteria was fulfilled: three patients $(5 \%)$ showed myocardial edema and five (9\%) non-ischemic myocardial injury (Table 4; Fig. 2). None of the three patients with myocardial edema (two patients with increased $\mathrm{T} 2$ relaxation times, one with pathological TIRM-Sequence) had conspicuous echocardiographic, electrocardiogram or laboratory chemistry findings.

The five patients with non-ischemic myocardial injury showed subepicardial LGE localisations and a mean EF of (mean EF 68\%. Three of these patients had normal findings in the further examinations. One patient showed wall movement disorders, pericardial effusion and myocarditis suspicious ST-changes, but the cardiac blood values were normal. Three patients had borderline hsTnT value without any echocardiographic or electrocardiogram abnormalities. All five findings were consistent with healed inflammation.

\section{Discussion}

Cardiac involvement in COVID-19 has been reported previously with conflicting data on prevalence and clinical relevance. Our study investigated post-COVID patients without previous heart disease presenting with persistent symptoms suspicious of myocarditis to a large cardiology practice. Using a comprehensive diagnostic approach including CMR,
Table 3 Magnetic resonance imaging findings of the entire study population

\begin{tabular}{lll}
\hline & & All patients $(n=56)$ \\
\hline Left ventricular end-diastolic volume index (LVEDVI) & $\mathrm{ml} / \mathrm{m}^{2}$ & $76.4 \pm 13.8$ \\
Left ventricular end systolic volume index (LVESVI) & $\mathrm{ml} / \mathrm{m}^{2}$ & $29.1 \pm 7.4$ \\
Left ventricular stroke volume index (LVSVI) & $\mathrm{ml} / \mathrm{m}^{2}$ & $47.3 \pm 8.3$ \\
Myocardial mass (MM) & $\mathrm{g} / \mathrm{cm}$ & $0.7 \pm 0.2$ \\
Ejection fraction & $\%$ & $62.3 \pm 5.0$ \\
Suspicious TIRM-findings & $n$ & $2(3.6)$ \\
T1 values & & \\
Mean & $\mathrm{ms}$ & $1016.0 \pm 28.2$ \\
Basal & $\mathrm{ms}$ & $1011.9 \pm 28.7$ \\
Mid-ventricular & $\mathrm{ms}$ & $1012.7 \pm 29.2$ \\
Apical & $\mathrm{ms}$ & $1021.7 \pm 35.6$ \\
T2 values & & \\
Mean & $\mathrm{ms}$ & $46.9 \pm 3.8$ \\
Basal & $\mathrm{ms}$ & $46.4 \pm 2.5$ \\
Mid-ventricular & $\mathrm{ms}$ & $47.2 \pm 2.7$ \\
Apical & $\mathrm{ms}$ & $48.8 \pm 3.1$ \\
Extracellular volume (ECV) map & $\%$ & $27.5 \pm 3.4$ \\
Late gadolinium enhancement (LGE) & $n$ & $7(12.5)$ \\
Subepicardial & $n$ & $5(8.9)$ \\
Subendocardial & $n$ & $1(1.8)$ \\
Intramyocardial & $n$ & $1(1.8)$ \\
\hline
\end{tabular}

Values are mean \pm standard deviation or $n(\%)$ 


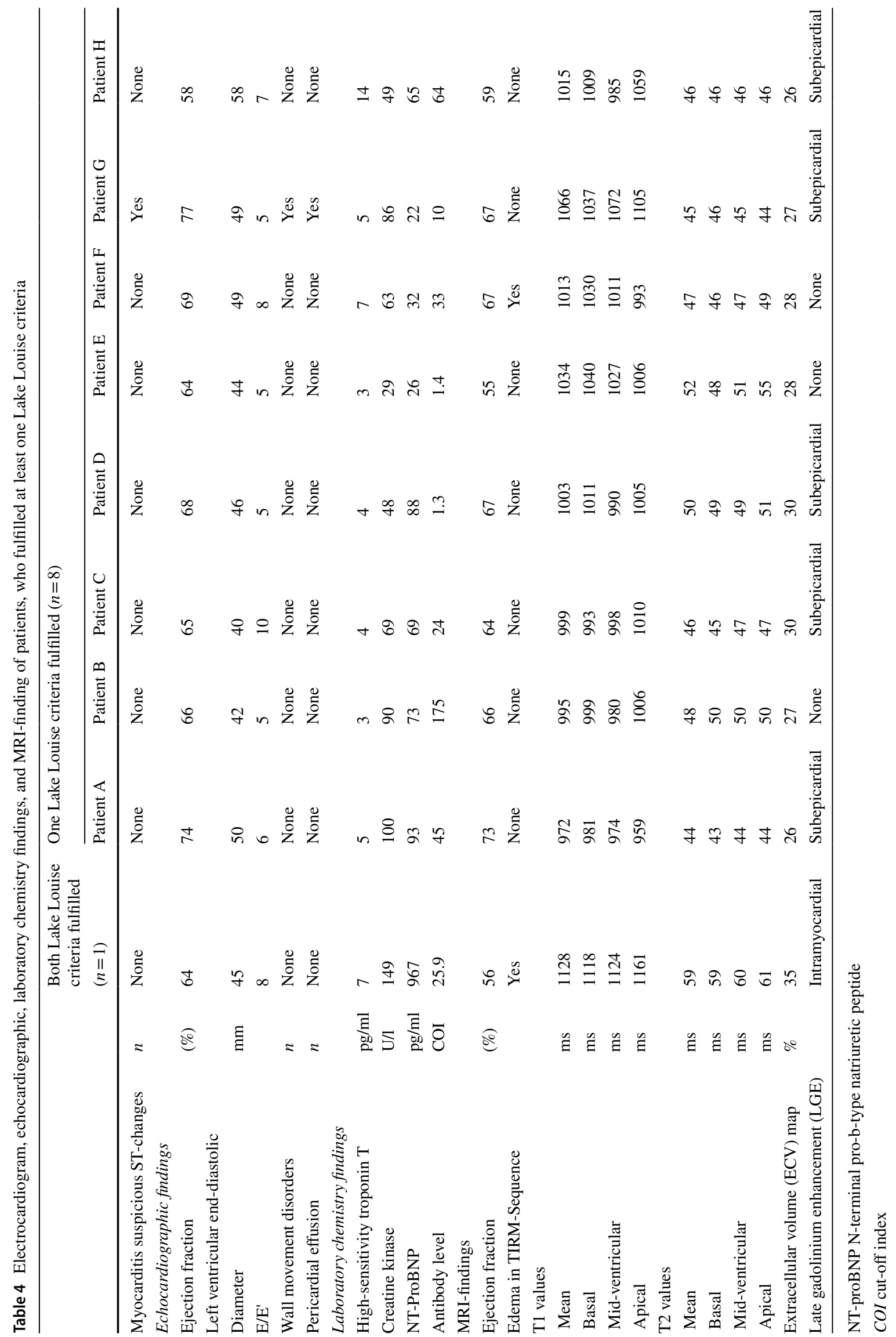


Fig. 1 MRI diagnosis of an acute myocarditis. MRI-findings of the patient who fulfilled both Lake Louise criteria with abnormal findings with emphasis basal inferolateral: nonischemic myocardial fibrosis proven by intramyocardial late gadolinium enhancement (A) and increased $\mathrm{T} 1$ times $(\mathbf{C})$ as well as signs of a myocardial edema with pathological TIRMSequence (B) and increased T2 relaxation time (D)

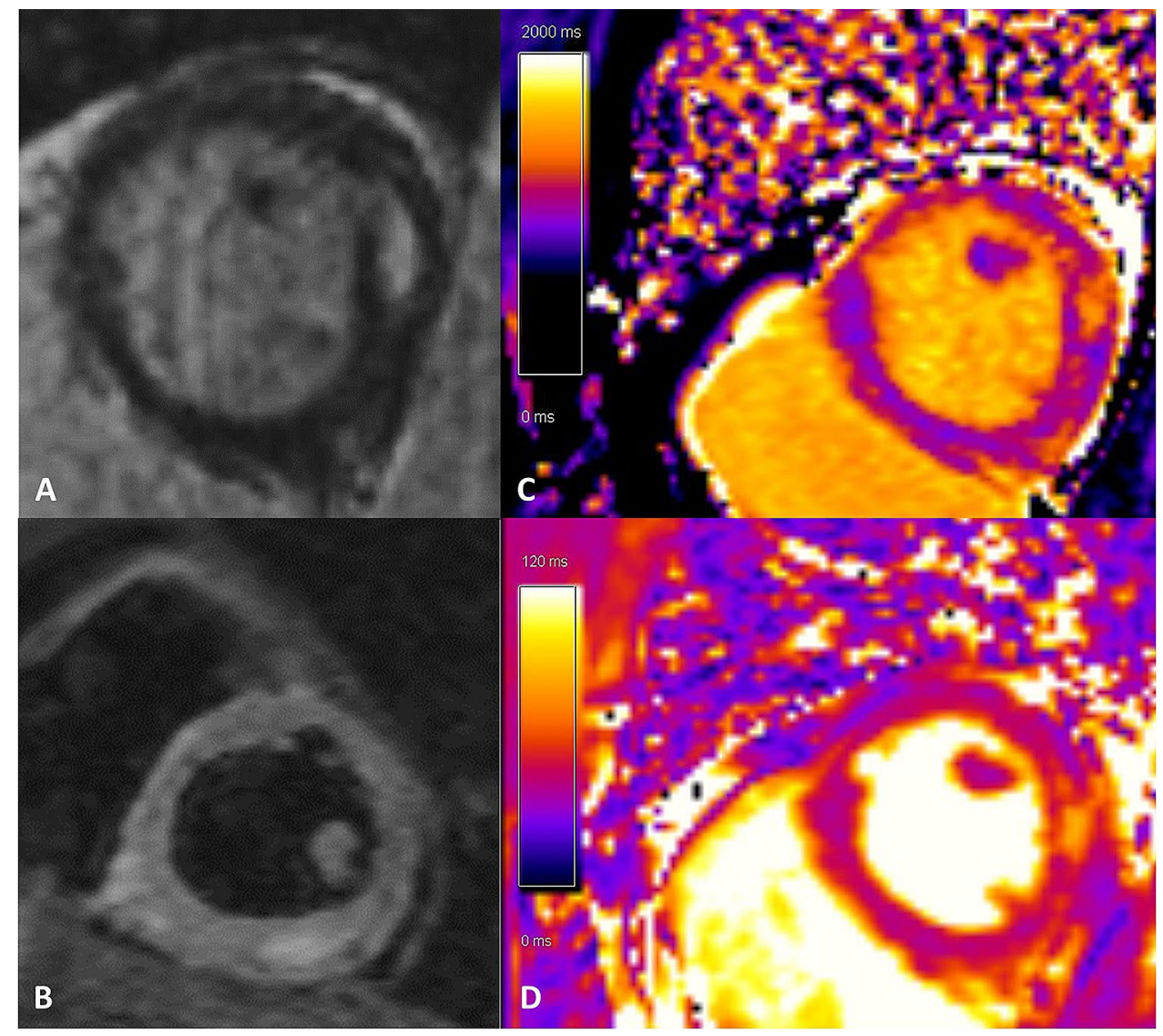

final diagnosis of myocarditis was infrequent and confirmed in a single out of 56 patients (2\%).

Previous studies have assessed myocardial involvement based on CMR findings in COVID-19 patients. The prevalence of abnormal CMR findings varied widely, between $1.4 \%$ and $78 \%$ [5-9]. The broad range may be explained by differences in diagnostic assessment as well as patient selection (e.g., competitive student athletes with an asymptomatic course versus patients with previous cardiac diseases requiring mechanical ventilation). Importantly, only the minority of the published studies used the 2018 Lake Louise criteria when interpreting the CMR findings [5, 8]. Increased $\mathrm{T} 1$ values or LGE both may not be specific for acute myocardial inflammation, but may also reflect previous myocardial injury of all ages [10]. The potential interference of previous cardiac disease is important to note, since up to $56 \%$ of hospitalized COVID-19 patients had pre-existing cardiovascular disease [11]. A recent CMR evaluation revealed comparable LGE rates in athletes with and without COVID-19 history [12]. A pathological study examining 40 hearts from patients dying of COVID-19 found myocyte necrosis in 35\%, which were mostly caused by microthrombi in epicardial coronary artery, myocardial capillaries, arterioles, and small muscular arteries [13].
On the other hand, myocardial oedema detected by $\mathrm{T} 2$ darkblood TIRM-Sequences or T2 mapping is not specific for myocarditis or inflammation in general [10].Therefore, the interpretation of all abnormal CMR findings as cardiac COVID-19 involvement may lead to an obvious overestimation of the diagnosis of myocarditis.

We used strict criteria, requiring fulfillment of both the 2018 Lake Louise criteria as well as pathological cardiac markers to diagnose myocarditis. Our findings are in line with autopsy reports as well as a recent CMR analysis in athletes recovering from COVID-19, suggesting that acute myocarditis is rare $[5,14]$. In the single patient with confirmed myocarditis but also in the additional eight requiring only one criterion of the modified Lake Louise criteria we found normal LV ejection fraction, which is an important prognostic marker in myocarditis [15]. However, the long-term significance of the abnormal CMR finding after COVID-19 recovery is not yet known.

In the eight patients of our study fulfilling only one of both myocarditis criteria, myocarditis cannot be ruled out completely. Particularly, myocardial edema which was observed in three of them could be related to increased vascular permeability mediated by endothelial angiotensin converting enzyme 2 (ACE2) which is an established functional receptor by which SARS-CoV-2 enters host target 
cells [16-18]. Of note, hsTNT as well as NTpro-BNP were normal in all of them.

The remaining five patients showed subepicardial LGE localisation as a marker of non-ischemic myocardial injury, which may be unspecific as we do not have CMR assessment before COVID-19. The echocardiographic and laboratory chemistry findings were inconspicuous, so we postulated healed inflammation that had passed at an unclear point in time.

\section{Clinical competencies}

A high number of patients recovered from SARS-CoV-2 infections present with persistent thoracic complaints suspicious of myocarditis. Our results suggest that definitive myocarditis is uncommon in post-COVID patients without previous cardiac disease. A single patient fulfilled all criteria of the modified Lake Louise criteria for diagnosing myocarditis. In additional eight patients myocarditis could neither be confirmed nor excluded. However, relevant myocarditis appeared unlikely as LV function was not impaired and laboratory markers of cardiac injury were inconspicuous. These findings are important to soften fears of long-term cardiac sequelae with possible psychosocial consequences in younger patients. In addition, the routine use of expensive (CMR) imaging in the diagnostic assessment of post-COVID patients with chest complaints may only be rarely needed. Our results suggest that a primary strategy using more conventional modalities such as ECG, echocardiography, and cardiac biomarkers may be sufficient to identify patients who could benefit from CMR.

\section{Limitations}

Since we excluded patients with known or newly diagnosed non-inflammatory heart disease, our findings are not transferrable to this group. However, acute SARS-CoV-2 infections affect a large number of younger patients with no prior illness, to which our findings should apply. Our study is limited by the restricted sample size and the use of a 1,5 Tesla scanner for CMR. Nevertheless, the robustness of the finding that myocardial inflammation is rare in our cohort is supported by the coherent laboratory results as well as the echocardiographic and CMR findings.

\section{Conclusion}

Definitive myocarditis was detected in a single out of 56 post-COVID patients without previous cardiac diseases presenting with persistent thoracic complaints suspicious of myocarditis. These data may provide some reassurance to symptomatic patients post-COVID regarding their risk of myocardial inflammation and argues against routine use of expensive modalities as CMR in all these patients.

Author contributions PB (corresponding author) performed the analysis and interpretation of data, drafted the manuscript, and approved the submission. AK performed the analysis and interpretation of data and drafted the manuscript. MS, AM, and EL-Last performed the analysis and interpretation of data. TV, AS, and RHM revised the manuscript critically for important intellectual content. HE conceived the study design, drafted the manuscript, and approved the submission.

Funding Open Access funding enabled and organized by Projekt DEAL. The study was sponsored by the Foundation of the Working Group of Leading Cardiological Hospital Doctors e.V. (ALKK).

Availability of data and material Not applicable.

Code availability Not applicable.

\section{Declarations}

Conflict of interest The authors have no conflicts of interest regarding the content of this study.

Ethics approval The study was approved by the local institutional review board (ethics committee of the Landesärztekammer Hessen).

Consent to participate/Consent for publication Included in written informed consent.

Open Access This article is licensed under a Creative Commons Attribution 4.0 International License, which permits use, sharing, adaptation, distribution and reproduction in any medium or format, as long as you give appropriate credit to the original author(s) and the source, provide a link to the Creative Commons licence, and indicate if changes were made. The images or other third party material in this article are included in the article's Creative Commons licence, unless indicated otherwise in a credit line to the material. If material is not included in the article's Creative Commons licence and your intended use is not permitted by statutory regulation or exceeds the permitted use, you will need to obtain permission directly from the copyright holder. To view a copy of this licence, visit http://creativecommons.org/licenses/by/4.0/.

\section{References}

1. Guo T, Fan Y, Chen M, Wu X, Zhang L, He T, Wang H, Wan J, Wang X, Lu Z (2020) Cardiovascular implications of fatal outcomes of patients with coronavirus disease 2019 (COVID-19). JAMA Cardiol 5:811-818. https://doi.org/10.1001/jamacardio. 2020.1017

2. Shi S, Qin M, Shen B, Cai Y, Liu T, Yang F, Gong W, Liu X, Liang J, Zhao Q, Huang H, Yang B, Huang C (2020) Association of cardiac injury with mortality in hospitalized patients with COVID-19 in Wuhan, China. JAMA Cardiol 5:802-810. https:// doi.org/10.1001/jamacardio.2020.0950

3. Inciardi RM, Lupi L, Zaccone G, Italia L, Raffo M, Tomasoni D, Cani DS, Cerini M, Farina D, Gavazzi E, Maroldi R, Adamo M, 
Ammirati E, Sinagra G, Lombardi CM, Metra M (2020) Cardiac involvement in a patient with coronavirus disease 2019 (COVID19). JAMA Cardiol 5:819-824. https://doi.org/10.1001/jamac ardio.2020.1096

4. Ferreira VM, Schulz-Menger J, Holmvang G, Kramer CM, Carbone I, Sechtem U, Kindermann I, Gutberlet M, Cooper LT, Liu P, Friedrich MG (2018) Cardiovascular magnetic resonance in nonischemic myocardial inflammation: expert recommendations. J Am Coll Cardiol 72:3158-3176. https://doi.org/10.1016/j.jacc. 2018.09.072

5. Starekova J, Bluemke DA, Bradham WS, Eckhardt LL, Grist TM, Kusmirek JE, Purtell CS, Schiebler ML, Reeder SB (2021) Evaluation for myocarditis in competitive student athletes recovering from coronavirus disease 2019 with cardiac magnetic resonance imaging. JAMA Cardiol. https://doi.org/10.1001/jamacardio. 2020.7444 .

6. Huang L, Zhao P, Tang D, Zhu T, Han R, Zhan C, Liu W, Zeng $\mathrm{H}$, Tao Q, Xia L (2020) Cardiac involvement in patients recovered from COVID-2019 identified using magnetic resonance imaging. JACC Cardiovasc Imaging 13:2330-2339. https://doi.org/10. 1016/j.jcmg.2020.05.004

7. Puntmann VO, Carerj ML, Wieters I, Fahim M, Arendt C, Hoffmann J, Shchendrygina A, Escher F, Vasa-Nicotera M, Zeiher AM, Vehreschild M, Nagel E (2020) Outcomes of cardiovascular magnetic resonance imaging in patients recently recovered from coronavirus disease 2019 (COVID-19). JAMA Cardiol 5:12651273. https://doi.org/10.1001/jamacardio.2020.3557

8. Kotecha T, Knight DS, Razvi Y, Kumar K, Vimalesvaran K, Thornton G, Patel R, Chacko L, Brown JT, Coyle C, Leith D, Shetye A, Ariff B, Bell R, Captur G, Coleman M, Goldring J, Gopalan D, Heightman M, Hillman T, Howard L, Jacobs M, Jeetley PS, Kanagaratnam P, Kon OM, Lamb LE, Manisty CH, Mathurdas P, Mayet J, Negus R, Patel N, Pierce I, Russell G, Wolff A, Xue H, Kellman P, Moon JC, Treibel TA, Cole GD, Fontana M (2021) Patterns of myocardial injury in recovered troponin-positive COVID-19 patients assessed by cardiovascular magnetic resonance. Eur Heart J 42:1866-1878. https://doi.org/10.1093/eurhe artj/ehab075

9. Raman B, Cassar MP, Tunnicliffe EM, Filippini N, Griffanti L, Alfaro-Almagro F, Okell T, Sheerin F, Xie C, Mahmod M, Mózes FE, Lewandowski AJ, Ohuma EO, Holdsworth D, Lamlum H, Woodman MJ, Krasopoulos C, Mills R, McConnell FAK, Wang C, Arthofer C, Lange FJ, Andersson J, Jenkinson M, Antoniades C, Channon KM, Shanmuganathan M, Ferreira VM, Piechnik SK, Klenerman P, Brightling C, Talbot NP, Petousi N, Rahman NM, Ho LP, Saunders K, Geddes JR, Harrison PJ, Pattinson
K, Rowland MJ, Angus BJ, Gleeson F, Pavlides M, Koychev I, Miller KL, Mackay C, Jezzard P, Smith SM, Neubauer S (2021) Medium-term effects of SARS-CoV-2 infection on multiple vital organs, exercise capacity, cognition, quality of life and mental health, post-hospital discharge. EClin Med. https://doi.org/10. 1016/j.eclinm.2020.100683

10. Friedrich MG, Cooper LT (2021) What we (don't) know about myocardial injury after COVID-19. Eur Heart J 42:1879-1882. https://doi.org/10.1093/eurheartj/ehab145

11. Agarwal MA, Ziaeian B, Lavie CJ, Fonarow GC (2020) Cardiovascular disease in hospitalized patients with a diagnosis of coronavirus from the Pre-COVID-19 Era in United States: National analysis from 2016-2017. Mayo Clin Proc 95:2674-2683. https:// doi.org/10.1016/j.mayocp.2020.09.022

12. Clark DE, Parikh A, Dendy JM, Diamond AB, George-Durrett K, Fish FA, Slaughter JC, Fitch W, Hughes SG, Soslow JH (2021) COVID-19 myocardial pathology evaluation in athletes with cardiac magnetic resonance (COMPETE CMR). Circulation 143:609-612. https://doi.org/10.1161/CIRCULATIONAHA.120. 052573

13. Pellegrini D, Kawakami R, Guagliumi G, Sakamoto A, Kawai K, Gianatti A, Nasr A, Kutys R, Guo L, Cornelissen A, Faggi L, Mori M, Sato Y, Pescetelli I, Brivio M, Romero M, Virmani R, Finn AV (2021) Microthrombi as a major cause of cardiac injury in COVID-19: a pathologic study. Circulation 143:1031-1042. https://doi.org/10.1161/CIRCULATIONAHA.120.051828

14. Halushka MK, Vander Heide RS (2021) Myocarditis is rare in COVID-19 autopsies: cardiovascular findings across 277 postmortem examinations. Cardiovasc Pathol. https://doi.org/10.1016/j. carpath.2020.107300.

15. Ali-Ahmed F, Dalgaard F, Al-Khatib SM (2020) Sudden cardiac death in patients with myocarditis: Evaluation, risk stratification, and management. Am Heart J 220:29-40. https://doi.org/10. 1016/j.ahj.2019.08.007

16. Pober JS, Sessa WC (2007) Evolving functions of endothelial cells in inflammation. Nat Rev Immunol 7:803-815. https://doi.org/10. 1038/nri2171

17. Li W, Moore MJ, Vasilieva N, Sui J, Wong SK, Berne MA, Somasundaran M, Sullivan JL, Luzuriaga K, Greenough TC, Choe H, Farzan M (2003) Angiotensin-converting enzyme 2 is a functional receptor for the SARS coronavirus. Nature 426:450-454. https://doi.org/10.1038/nature02145

18. Turner AJ, Hiscox JA, Hooper NM (2004) ACE2: from vasopeptidase to SARS virus receptor. Trends Pharmacol Sci 25:291-294. https://doi.org/10.1016/j.tips.2004.04.001 